\title{
New pest management center based at UC Davis
}

\section{The new Western Pest Management Center at UC Davis will advise federal agencies on research needs. Innovative strategies, such as broadcasting oats to prevent weeds in alfalfa, below, will be explored.}

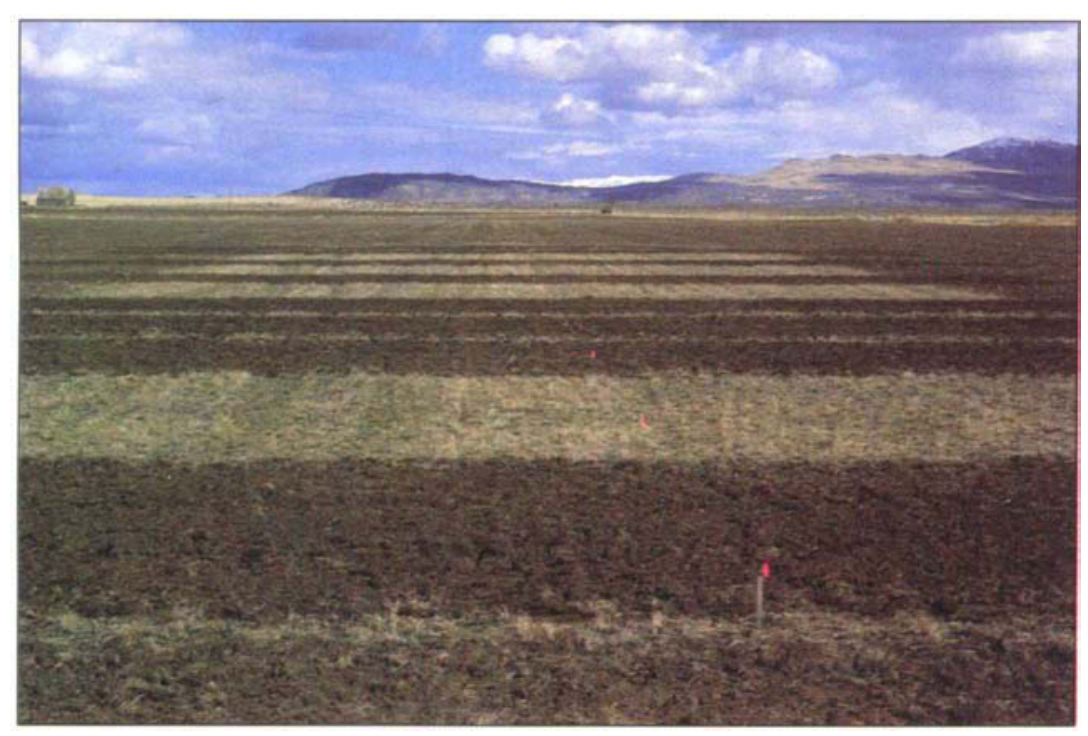

mote better coordination between the two agencies. Passed in 1996, FQPA required EPA to re-evaluate existing pesticides for possible impacts on children, as well as the cumulative effects of various chemicals in the environment.

"FQPA has not had its full impact yet," Melnicoe said. "As we lose broad-spectrum pesticides, IPM (integrated pest management) and sustainable agriculture are going to be key players in replacement strategies for pest control."

During the first year, the center plans to develop 20 new crop profiles - detailed monographs of major pest issues for particular commodities, and will update 20 to 25 existing crop profiles. "UC personnel have been instrumental in reviewing, drafting and prioritizing 47 crop profiles that have been completed already. I foresee UC's continued active involvement in crop profiles," Melnicoe said.

The center will also develop two strategic pest management plans to be determined by an advisory committee or commodity group. These plans involve bringing together a commodity's stakeholders to outline a complex matrix of pest problems and solutions. "We then create a big 'to do' list of research, educational and regulatory needs," Melnicoe said. "This gives USDA and EPA a good handle on where they need to focus resources, and provides a solid foundation for decisionmaking."

The strategic planning process is growerdriven, Melnicoe said. "If it's not important to the grower, it's not important."

Melnicoe urged researchers, farm and extension advisors, growers and others to communicate their concerns and needs to the center. "I'd like to know what they're working on, in order to identify pest management issues as they arise."

For more information, go to www.wrpmc.ucdavis.edu, or call Melnicoe at (530) 754-8378 or assistant director Linda Herbst at (530) 752-7010. 